\title{
MOBILIZAÇÃO NAS FAVELAS CARIOCAS CONTRA OS IMPACTOS DA PANDEMIA DA COVID-19
}

MOBILIZATION IN THE FAVELAS CARIOCAS AGAINST IMPACTS OF THE COVID-19 PANDEMIC

Gláucio Glei Maciel

Mestre e doutor em Serviço Social pela Pontifícia Universidade Católica do Rio de Janeiro (PUC-Rio), pesquisador associado do Laboratório de Estudos Urbanos e Socioambientais (LEUS/PUC-Rio) e membro do Coletivo Malês.

\section{Rafael Soares Gonçalves}

Mestre e doutor em História pela Universidade de Paris VII, com pós-doutoramento em Antropologia pela École des Hautes Études en Sciences Sociales (EHESS). Professor do Departamento de Serviço Social da Pontifícia Universidade Católica do Rio de Janeiro (PUC-Rio). Cientista do Nosso Estado pela Fundação de Amparo à Pesquisa do Estado do Rio de Janeiro (FAPERJ) e bolsista de produtividade do Conselho Nacional de Desenvolvimento Científico e Tecnológico (CNPQ). Coordenador do Laboratório de Estudos Urbanos e Socioambientais (LEUS/PUC-Rio). 


\section{RESUMO}

Apesar de o coronavírus ter se expandido inicialmente nos bairros nobres da cidade do Rio de Janeiro, rapidamente se difundiu pelas favelas e trouxe à tona o impacto do enfraquecimento atual das políticas sociais. A partir de entrevistas, que vem sendo realizadas desde janeiro de 202I, o presente artigo pretende abordar as consequências da pandemia de coronavírus nas favelas cariocas, analisando, primeiramente, a precariedade das políticas públicas nesses locais e os desdobramentos dessa realidade no contexto da Covid-I9. Pretende-se, ainda, questionar a noção das favelas como espaços de ausências para compreender a riqueza e a criatividade dos saberes e conhecimentos que ali circulam e que se manifestam justamente em contextos de crises, como a da pandemia atual.

Palavras-chave: Covid-I9; favelas cariocas; formas de resistência social.

\section{ABSTRACT}

Although COVID-I9 initially spread in the city's noble neighborhoods, the pandemic quickly spread through the favelas of the city of Rio de Janeiro and brought to light the impact of the current weakening of social policies. Based on interviews, which have been conducted since January 202I, this article intends to address the impact of the coronavirus in Rio de Janeiro's favelas, analyzing, firstly, the precariousness of public policies in the favelas and the unfolding of this reality in the context of Covid-I9. It is also intended to question the notion of favelas as spaces of absences to understand the richness and creativity of the knowledges that circulate there and that manifest themselves precisely in contexts of crises, such as that of the coronavirus pandemic.

Keywords: Covid-I9, Rio de Janeiro favelas, forms of social resistance. 


\section{Introdução}

Apesar de a pandemia ter chegado ao Rio de Janeiro através de pessoas vindas da Europa, sobretudo da Itália, e ter se alastrado inicialmente pelos bairros da Zona Sul e pela Barra da Tijuca, rapidamente compreendeu-se que a Covid-ı não era "elitista", mas "democrática". A doença rapidamente começou a se espalhar por bairros da Zona Oeste, cidades da Baixada Fluminense, assim como pelas favelas.

Diante da ausência inicial de uma vacina ou de um medicamento realmente eficaz, a indicação mais difundida para o controle da pandemia foi o isolamento social e o aumento de medidas preventivas de higiene. Isso obviamente foi muito mais complicado em áreas faveladas diante da enorme densidade habitacional. Como manter isolados doentes em moradias onde inúmeras pessoas partilham um só ambiente? Como exigir a lavagem periódica das mãos, de embalagens de produtos ou de roupas em lugares com abastecimento precário de água? A pandemia trouxe à tona realidades cotidianas de parcela importante da população carioca que normalmente só se manifestam em contextos de crises.

Além disso, para muitos dos moradores de favelas, suas atividades profissionais não lhes permitem atuar de forma remota, então precisaram continuar a se locomover para trabalhar. Algumas atividades foram, aliás, profundamente impactadas pela restrição de locomoção e pelo isolamento, como a de ambulantes ou diaristas. Vale destacar que esses trabalhadores estão muito expostos ao risco de contaminação pela Covid-19, e, do ponto de vista financeiro, foram mais afetados, visto que não tinham garantias trabalhistas.

Também cabe ressaltar que os níveis elevados de informalidade e a ausência de direitos que atingem os trabalhadores não são resultados da pandemia. O neoliberalismo acirra as transformações no âmbito do trabalho através das redefinições dos sistemas de proteção social e da perda de direitos e precarização das políticas sociais. Segundo Antunes (2020, p. 09), "são resultados da combinação letal entre a crise estrutural do capitalismo, que destrói sistematicamente a legislação social protetora do trabalho, e uma crise sociopolítica sem precedentes".

Além disso, muitos moradores das favelas trabalham também em atividades consideradas essenciais, e foram importantes para que o isolamento do restante da população pudesse se realizar, como entregadores ou comerciários. Para eles, não foram oferecidas condições adequadas de transporte, tampouco, ao menos no início da pandemia, equipamentos de proteção para exercer suas funções com segurança. As dificuldades se multiplicaram para essas famílias quando, sem escolas, muitos pais não tinham onde deixar

\footnotetext{
${ }^{1}$ Para saber mais sobre o assunto acesse: <https://ufrn.br/imprensa/noticias/35459/domesticas-estao-entre-as-mais-expostas-acontaminacao-pela-covid-19>.
} 
seus filhos. Com as escolas fechadas, muitas das crianças membros dessas famílias ficaram aglomeradas em casas de cuidadoras para que seus pais pudessem trabalhar.

Em consonância com Harvey (2020, p. 32), é possível afirmar que essa parcela dos trabalhadores "está na vanguarda e tem o peso de ser a força de trabalho que está com o maior risco de contrair o vírus por meio de seus empregos ou de ser demitida sem ter garantias por causa da contenção econômica imposta pelo vírus". São essas pessoas que compõe o grupo que não pode trabalhar em casa. Ainda segundo o autor, "isso aumenta a divisão social [...] da mesma maneira que aprendi a chamar os terremotos na Nicarágua (1973) e na Cidade do México (1995) de 'terremotos de classe', o progresso do COVID-I9 exibe todas as características de uma pandemia de classe, de gênero e de raça" (p. 32 ).

Essas são apenas pequenas situações que começaram a contrastar com as primeiras imagens da quarentena europeia, com as pessoas cantando nos balcões de suas casas. Era notório, desde o início, que tal abordagem era romantizada (mesmo para o contexto europeu) e completamente fora da realidade das favelas cariocas. De antemão, era necessário retrabalhar a informação e fazer com que o combate ao coronavírus se inserisse no cenário brasileiro e, mais especificamente, carioca. O trabalho incansável de comunicadores comunitários, acadêmicos e lideranças sociais procurou trazer as favelas para o centro do debate, forçando inclusive a grande mídia a alterar profundamente sua maneira de abordar a pandemia (CLAPP et al., 2020, p. I4). ${ }^{2}$

O presente artigo pretende abordar o impacto do coronavírus nas favelas cariocas, analisando, primeiramente, a precariedade das políticas públicas nas favelas e os desdobramentos dessa realidade no contexto da Covid-19. Pretende-se, posteriormente, questionar a noção das favelas como espaços de ausências para compreender a riqueza e a criatividade dos saberes e conhecimentos que ali circulam e que se manifestam justamente em um cenário de crises. Retoma-se aqui artigo anterior dos autores (GONÇALVES; MACIEL, 2020), agregando dados das primeiras entrevistas realizadas junto a moradores de favelas durante a pesquisa de pós-doutorado do primeiro autor.

\footnotetext{
${ }^{2}$ Esse foi o objetivo inicial, por exemplo, do Movimento Seja Vivo, coordenado pelos professores Rafael Soares Gonçalves (PUC-Rio) e Celso Sanchez (UNIRIO), e que congregou vários profissionais, lideranças e moradores de favelas para levar informação de qualidade para esses espaços. Mais informações: <https://www.facebook.com/SejaVivo-106051687710815/>.

${ }^{3}$ Trata-se de projeto de pós-doutoramento, financiado pela FAPERJ e cujo título é "Covid 19 e as formas de resistência social nas favelas cariocas". Os autores pretendem mapear as redes de apoio existentes nas favelas no contexto da pandemia, procurando identificar conceitos e ferramentas inovadores nas práticas ali existentes
} 


\section{A pandemia e as favelas}

A pandemia causada pelo coronavírus trouxe à tona o impacto do enfraquecimento atual das políticas sociais brasileiras. A expectativa é de um acentuado aumento da desigualdade social nas principais cidades do país, sobretudo no Rio de Janeiro. Por outro lado, reforçou a importância do Sistema Único de Saúde (SUS), mas também como seu sucateamento atinge duramente a população mais vulnerável. Em consonância com esse raciocínio, Ferreira (2018, p. 9), ao criticar a precarização do SUS, destaca que:

Diariamente é noticiado nos jornais e demais meios de comunicação os problemas enfrentados pelos brasileiros na utilização dos serviços de saúde pública. Dificuldade de acesso, carência de medicamentos e filas intermináveis são alguns dos exemplos. Essa situação de precarização abre espaço para que o setor privado atue na política de saúde. E assim essa política passa a ser analisada como mercadoria.

A situação da saúde pública já era particularmente difícil na cidade do Rio de Janeiro, com hospitais sucateados e equipes com salários atrasados. Em vez de empregar recursos para investir nos equipamentos de saúde existentes revertendo a precariedade da saúde, os recursos emergenciais no contexto da pandemia se voltaram sobretudo para hospitais de campanha. ${ }^{4}$ Com acusações de corrupção que resultaram no impeachment do governador, alguns desses hospitais nem chegaram a ser inaugurados diante da queda das taxas de infecção na cidade. As respostas de líderes dos poderes públicos não miraram o atendimento básico, tampouco a obtenção de equipamentos de segurança para os profissionais, nem a testagem em massa da população.

Se a resposta à crise sanitária de estados e municípios foi relativamente rápida em alguns casos, a do governo federal foi catastrófica. Como um profeta do caos, o presidente minimizou a doença e, sem nenhuma empatia, vem desdenhando dos impactados e mortos. ${ }^{5}$ Estabeleceu uma falsa dicotomia entre vida e economia, que, no fundo, vem provocando milhares de mortes e reforçando de modo exponencial a crise econômica. Junto com a falta de gestão federal, com seus sucessivos ministros da saúde e sem nenhuma coordenação nacional, o povo assiste estarrecido ao colapso dos sistemas públicos de saúde em cada estado da nação (CLAPP et al., 2020, p. IO).

\footnotetext{
${ }^{4}$ Para saber mais sobre o assunto acesse: <https://politica.estadao.com.br/blogs/estadao-verifica/denuncias-de-corrupcao-nasaude-do-rio-motivam-desinformacao-nas-redes/>.

${ }^{5}$ Ver: <https://oglobo.globo.com/brasil/bolsonaro-volta-minimizar-pandemia-chama-covid-19-de-gripezinha-1-24319177>.
} 
O brasileiro ficou chocado com a falta de oxigênio nos hospitais de Manaus (AM), enquanto o Ministério da Saúde fazia campanha para a distribuição local de hidroxicloroquina. O investimento federal na vacinação ocorreu tardiamente, não conseguindo engrenar de maneira satisfatória até ao menos o final do mês de maio de $202 \mathrm{I}$. O ritmo da produção de vacinas continua aquém da estrutura existente no país por causa dos inúmeros conflitos suscitados pelo governo brasileiro em relação aos chineses, o que vem dificultado a chegada de insumos do país asiático. Apesar de centenas de milhares de mortos, o governo ainda defende a administração de medicamentos já comprovadamente ineficazes. A má gestão da pandemia suscitou inclusive a abertura de uma Comissão Parlamentar de Inquérito (CPI) no Senado Federal.

Esperava-se, na situação atual, outro tipo de postura do Estado, em suas diferentes esferas. A ênfase em hospitais de campanha, necessários em emergências, poderia ter sido complementada com a reabilitação dos inúmeros leitos abandonados nos hospitais da cidade, sobretudo da rede federal. Da mesma maneira, seria importante uma maior reflexão sobre o atendimento básico, com o acompanhamento dos moradores desde os primeiros sintomas, de modo a evitar o contágio. A falta de testes e de investimentos no atendimento básico produziram um número imenso de subnotificações.

A cidade do Rio de Janeiro, como um dos epicentros da pandemia no país, apresentou uma elevada taxa de letalidade, sobretudo de pobres e negros. A atuação dos poderes públicos levou a uma naturalização das mortes, o que reforça a necropolítica (MBEMBE, 20I6) brasileira como política de Estado. ${ }^{6}$ Segundo reportagem do jornal O Globo, de Io de agosto de 2020, um estudo do Instituto de Pesquisa Econômica Aplicada (Ipea) mostrou que 79,6\% dos 6.735 óbitos registrados na capital até o dia I 3 de junho ocorreram nas áreas mais vulneráveis da cidade, a maioria longe da região da Zona Sul, Barra e Grande Tijuca, que têm Índice de Desenvolvimento Social (IDS) mais alto. Mesmo tendo mais idosos, principal grupo de risco para a doença, essas regiões com população de maior poder aquisitivo tiveram uma taxa de letalidade média de Io\%, metade da registrada nos locais mais carentes, de $20 \%$ em média.

Essa situação é reforçada pelo aumento surreal das operações policiais nas favelas cariocas, mesmo diante da necessidade de isolamento social. Os primeiros meses de 2020 foram os mais sangrentos, fortalecendo a mencionada necropolítica. Há inúmeros relatos de moradores e militantes que tiveram de suspender atividades contra a Covid-I9 por causa de

\footnotetext{
${ }^{6}$ A porcentagem de mortes em hospitais públicos, segundo reportagem do site Uol, do dia 21 de junho de 2020 , era o dobro dos hospitais privados. Disponível em: <https://noticias.uol.com.br/saude/ultimas-noticias/redacao/2020/06/21/mortalidade-em-utispublicas-para-covid-19-e-o-dobro-de-hospitais-privados.htm>. Acesso em: ago. 2020.

${ }^{7}$ Disponível em: <https://oglobo.globo.com/rio/estudo-do-ipea-ve-questao-social-em-mortes-por-covid-no-rio-maioria-dasvitimas-vivia-em-areas-mais-pobres-da-cidade-24562094>. Acesso em: ago. 2020.
} 
operações policiais. ${ }^{8}$ Até junho de 2020, o Rio de Janeiro foi o estado com o maior número de operações policiais (2.772) e também de mortos por essas operações $(483){ }^{9}{ }^{9}$

Diante disso, o Ministro do Supremo Tribunal Federal (STF), Edson Fachin, concedeu liminar temporária, em 5 de junho de 2020 , proibindo operações policiais em favelas do Rio de Janeiro. A Arguição de Descumprimento de Preceito Fundamental (ADPF) no 635 das Favelas foi uma resposta à iniciativa dos diferentes segmentos sociais contra a política de segurança do Estado. ${ }^{10}$ Apesar da ADPF, a operação na Favela do Jacarezinho, no dia 6 de maio de 202I, deixou pelo menos um policial e 28 moradores mortos, muitos com sinais de execução. ${ }^{11}$

Um dos interlocutores da pesquisa realizada pelos autores, em maio de 202 I, descreveu a angústia de presenciar operações policiais em plena pandemia:

[...] Além de enfrentar o vírus, a discriminação, o desemprego, a fome etc., temos que enfrentar as operações policiais. Na minha casa, ninguém sai ou entra sem verificar os sinais da presença da polícia, pois temos medo de ser parte das estatísticas. (Morador 2 da Favela da Mangueira)

Em termos urbanísticos, a pandemia trouxe enormes desafios para aplicar as medidas de prevenção nas favelas, como, por exemplo, a precariedade crônica do abastecimento de água. ${ }^{12}$ Da mesma maneira, alguns moradores de favelas já anteriormente atingidas por epidemias de doenças respiratórias, como a Rocinha, manifestavam a preocupação com uma expansão descontrolada do vírus. Observa-se, ainda, o impacto da ausência de políticas públicas de urbanização de favelas nos últimos anos. Os projetos de urbanização realizados, como o do Governo do Estado do Rio de Janeiro com recursos do Programa de Aceleração do Crescimento (PAC) durante a preparação da cidade para os Jogos Olímpicos, foram muito criticados por terem priorizado equipamentos com grande visibilidade, como teleféricos, mas com pouca utilidade para os moradores e em detrimento das reais necessidades da população.

\footnotetext{
${ }^{8}$ Verifique um dos casos em: <https://noticias.uol.com.br/cotidiano/ultimas-noticias/2020/05/21/entrega-de-cestas-basicas-einterrompida-por-tiroteio-no-rj-jovem-morre.htm>.

${ }^{9}$ Disponível em: <https://www.redetv.uol.com.br/jornalismo/redetvnews/videos/seguranca/rj-tem-o-maior-numero-de-mortosem-operacoes-policiais-diz-pesquisa>. Acesso em: ago. 2020.

${ }^{10}$ Após a proibição das operações, foram constatatas menos 72,5\% de mortes no Rio, como destaca o jornal Brasil de Fato. Ver: $<$ <ttps://www.brasildefato.com.br/2020/08/04/stf-mantem-suspensao-das-operacoes-policiais-em-favelas-durante-pandemia.

${ }^{11}$ Disponível em: <https://g1.globo.com/rj/rio-de-janeiro/noticia/2021/05/06/tiroteio-deixa-feridos-no-jacarezinho.ghtml>. Acesso em: maio 2021.

12 Ver: <https://www.cnnbrasil.com.br/nacional/2020/03/28/moradores-e-defensoria-publica-denunciam-falta-de-agua-durante-apandemia-no-rio $>$.
} 
O abandono pelo Estado também pode ser verificado na carência de políticas socioeconômicas reparadoras durante a pandemia. A oferta de serviços de prevenção e cuidados com a Covid-I9 foi insuficiente para atender à crescente demanda dos moradores das favelas. Ciente desse fato, as populações faveladas identificaram a necessidade de fomentar a criação de novas formas de resistência social, incluindo as redes de apoio em seu plano de sobrevivência. As redes de troca e apoio nas favelas hoje são espaços importantes de atenção ao enfrentamento da pandemia e da pobreza decorrente de um processo histórico, que vem se acirrando e certamente continuará elevado por muito tempo.

\section{Formas de resistência nas favelas cariocas}

As medidas contra o coronavírus e a recessão global podem perturbar o funcionamento da economia, com consequências potencialmente terríveis. Sem uma ação imediata, corre-se o risco de assistir a uma emergência alimentar global - com impactos em longo prazo para milhões de pessoas.

De acordo com a Organização Internacional do Trabalho (OIT), ${ }^{13}$ a crise socioeconômica ampliada pode deixar 25 milhões de pessoas sem trabalho e aprofundar a pobreza no mundo, com uma perda de renda para os trabalhadores de US\$ 3,4 trilhões, em 2020. Diante disso, a previsão, segundo a Organização das Nações Unidas (ONU), ${ }^{14}$ é de que o PIB do planeta sofra um golpe de US\$ 2 trilhões, jogando a economia mundial em uma profunda recessão. Ainda que o efeito previsto seja mitigado por ações governamentais, é previsível que no Brasil deve aumentar o desemprego e a precarização do trabalho e da saúde pública. Isso se manifestará com uma maior degradação ambiental sob um contexto mais dramático da necropolítica.

Outro morador da Favela da Mangueira contou sobre a perda do emprego, realidade de milhares de trabalhadores na cidade:

[...] fiquei sem emprego no início da pandemia, estou até agora sem conseguir nada formal... Se souber de alguma coisa, avisa. Ao me ver nessa situação, fui buscar apoio de parentes. Depois comecei a catar material reciclado, não rende muito dinheiro, mas dá para comprar algum alimento. (Morador I da Favela da Mangueira)

\footnotetext{
13 Disponível em:<https://news.un.org/pt/story/2020/03/1707842>. Acesso em: ago. 2020.

14 Disponível em: <https://noticias.uol.com.br/colunas/jamil-chade/2020/03/18/pandemia-pode-causar-desemprego-de-25milhoes-de-pessoas.htm>. Acesso em: ago 2020.
} 
Esse relato expõe a situação atual dos trabalhadores, sobretudo dos negros, que já se encontravam à margem da sociedade. Observa-se, assim, o risco de um maior empobrecimento das populações periféricas no Brasil, mais especificamente, no Rio de Janeiro. A precariedade da resposta do Estado justificou e suscitou o fortalecimento de práticas de resistência social e a estruturação e ampliação de redes de sobrevivência, tanto no plano epidemiológico quanto no aspecto econômico.

As mudanças ocasionadas pela Covid-I9 tendem a influenciar ainda mais as políticas socioeconômicas no mundo, diminuindo seu fluxo (que já é precário), desestimulando sua prática e mudando até o perfil daqueles que, de certa maneira, conseguiram algum tipo de apoio de políticas sociais e do próprio local de trabalho (ANTUNES; ALVES, 2004). Apesar das vergonhosas filas nos bancos para obter o benefício emergencial, sua concessão pelo governo federal, sob iniciativa do parlamento, minorou os impactos da crise econômica para a população mais vulnerável. No entanto, o fim do pagamento desse benefício e seu retorno tardio em valores muito menores fazem com que o horizonte econômico no pós-pandemia pareça bem complexo.

O morador entrevistado da Favela do Cerro Corá, em abril de 202I, relata suas dificuldades econômicas e indica algumas iniciativas de solidariedade:

Sempre trabalhei no campo do turismo. Já deu mais dinheiro... Agora, com a pandemia, o número de turistas aqui no Corcovado baixou. Ou seja, continua pingando [entrando dinheiro], mas é pouco. Então, eu e minha esposa montamos uma barraca lá na Praia do Flamengo... O lucro não está bom: pouca gente, fiscalização e proibição quebram a arrecadação. Mas está de boa. O tempo que sobra, além de me dedicar à família, também ajudo a galera a enfrentar a Covid-I9. Já lavei muitos becos, levei muitas cestas básicas para aqueles que têm pouca mobilidade e às vezes compro alguma mercadoria (cerveja, água e refrigerante) para a galera vender em Copacabana. (Morador 4 da Favela do Cerro Corá, grifo nosso)

Por causa da supressão de direitos sociais que as relações econômicas impõem cada vez mais, as atividades de resistência social valorizam o autêntico, o que se origina localmente e que foge do homogêneo (ZAOUAL, 2009). Os desafios atuais da gestão da crise da saúde nas favelas passam por ações locais de enfrentamento ao coronavírus e a suas consequências. Tais ações potencializaram trocas de experiências e a geração de receitas significativas através da circulação dos recursos entre os próprios moradores. As pautas construídas pelos grupos minoritários se puseram em diálogo e, por vezes, em conflito, com as respostas do Estado, como mostram nas entrevistas a seguir, realizadas em maio de $202 \mathrm{I}$. 
Desde que cheguei ao morro, há mais de 20 anos, tenho esse pequeno comércio [padaria]. Daqui saiu o dinheiro para construir minha casa e sustentar a família. Agora é esse mesmo lugar que segura as pontas [finanças], principalmente dos meus filhos, que ficaram sem emprego. Eu ajudo no que posso, mas também coloco meu menino e minha menina para ajudarem outras pessoas que necessitam mais. Para isso, meus garotos se juntaram com o pessoal lá do asfalto e estão arrecadando dinheiro pela internet, e com isso compram alimentos de pequenos agricultores e distribuem na favela. (Morador I da Favela de São Carlos, grifo nosso)

A minha situação está precária. Tem seis anos que não consigo trabalho. Faço bicos como ajudante de pedreiro, às vezes, quando sobra um dinheiro, compro mercadoria e vou vender na praia... Mas, com a pandemia, tudo ficou mais difícil. Passei a receber ajuda das igrejas e de pessoas que trabalham em organizações sociais. Porém, não fico parado... Apoio um grupo de moradores que vão quase todos os dias de casa em casa para saber se tem uma pessoa (idosos e solitários) necessitando ir ao médico, ou de material de limpeza, prato de comida... sabe comoé? A gente não tem muito, mas se ajuda [...]. (Morador I da Favela Final Feliz)

Em suma, trata-se de inovações importantes de articulação de empreendedores locais, moradores, grupos de ativistas e lideranças. Tais iniciativas fomentaram redes locais de negócios em direção a um objetivo de sobrevivência comum, minimizando os impactos negativos da crise e maximizando a distribuição de alternativas. A observação da realidade atual indica que a chave de quase todas as respostas contemporâneas aos desafios elencados está no desenvolvimento de um planejamento participativo, que estimule a democratização das receitas e promova formas sustentáveis de lidar com os recursos escassos. Diante da Covid-I9 e do acirramento das problemáticas sociais que se avizinham, espera-se que seus resultados proporcionem uma gestão pública também democrática, de maneira que as partes interessadas possam participar nos processos de decisão ou interferir na condução do processo naquilo que lhes afeta diretamente (HALL, 200I; OLIVEIRA, 2008).

Além da questão econômica, observam-se práticas de resistência social nas favelas com medidas inovadoras no tratamento do coronavírus. O esforço da mobilização nesses locais se iniciou com os comunicadores comunitários para trazer informações fidedignas sobre o vírus para as favelas. Tendo em vista o desconhecimento, a elitização dos meios de comunicação tradicionais em tratar o tema e a profusão das fake news, isso foi um grande desafio para tais 
comunicadores. Chama atenção não só a distribuição dos recursos arrecadados, mas sobretudo a transmissão de conhecimentos (FLEURY; MENEZES, 2020, p. 279).

Além disso, foi necessária muita criatividade por parte dos comunicadores para fazer chegar a informação aos moradores. Foram usados portais locais de informação, grupos de WhatsApp, redes sociais, caminhões de som, cartazes e o tradicional boca a boca. Em algumas favelas, foi pintado o número de infectados e de mortos em muros para que a população pudesse acompanhar o crescimento da pandemia. Como analisam Menezes et al. (202 I), o trabalho feito na construção dos painéis comunitários questiona a ação do Estado e reverte a tentativa de tornar invisível a realidade da pandemia nas favelas, bem como tensionam um campo de disputa em torno da verdade da pandemia em favelas e periferias.

A subnotificação foi algo constante, sobretudo nas favelas. Segundo o presidente da Associação de Moradores do Jacarezinho, Leonardo Pimentel: “[...] mais de 20 mil pessoas já pegaram a doença só no Jacarezinho, pela enormidade de relatos que recebemos. Para mim, a pandemia foi um sacode. A corda arrebentou mesmo para o lado mais fraco". ${ }^{15} \mathrm{O}$ problema da subnotificação estimulou experiências inovadoras, como o Painel Unificador Covid-ıg nas Favelas, criado por uma rede autônoma de movimentos sociais, em julho de 2020. Trata-se de uma iniciativa colaborativa, cujo objetivo principal foi apoiar os esforços de prevenção realizados por movimentos comunitários a fim de informar moradores e pressionar por políticas públicas necessárias, além de fornecer uma visão mais precisa do impacto da pandemia nesses territórios. Com apoio técnico da Fiocruz, o painel fornece dados para que os movimentos divulguem diariamente em portais de notícias comunitárias e redes sociais informações sobre o andamento da pandemia.

Diante do caos instalado, a grande lição que fica é justamente do movimento associativo de favelas. Além do esforço de comunicação, outras iniciativas foram se manifestando em diversas favelas, demonstrando não apenas solidariedade, mas um fino conhecimento adquirido de mobilização em contextos de crise (GONÇALVES, 2015): distribuição de cestas básicas e kits de higiene, instalação de pontos de água, mapeamentos de doentes, sanitização das ruas das favelas, distribuição de recursos para compra de gás e estratégias de isolamento. Tal mobilização se apresentou de maneira muito diversa dependendo da favela, mas apresentou uma lógica de rede em que parcerias de ideias e recursos circularam entre os grupos envolvidos, como a campanha coletiva de arrecadação de dinheiro nas favelas, que mobilizou recursos para diferentes movimentos locais. ${ }^{16}$

\footnotetext{
${ }^{15}$ Ver: <https://oglobo.globo.com/rio/estudo-ve-questao-social-em-mortes-por-covid-no-rio-796-das-vitimas-ate-13-de-junhoviviam-em-areas-mais-pobres-24562081>.

${ }^{16}$ Ver: <https://www.covid19nasfavelas.meurio.org.br/\#block-14404>.
} 
Pode-se citar, ainda, as iniciativas realizadas pelo Grupo Eco, do Morro Santa Marta, que entregou milhares de máscaras e cestas básicas, contando com o apoio de igrejas (católica e evangélica), centros espíritas e associação local de moradores como pontos de entrega (GRUPO ECO, 2O2O). Chegou-se a contratar uma moradora, ex-agente de saúde da Clínica da Família e assistente social, para abordar as famílias com o objetivo de saber quantos morreram vítimas de Covid-19 e em que condições (GRUPO ECO, 2020).

O momento aponta, pois, para a retração das políticas sociais, e, em contrapartida, para a urgência em dialogar com as formas criativas de lidar com a pandemia nas favelas. As populações periféricas, sobretudo as faveladas, se mostram mais flexíveis para responder às demandas do cotidiano. Entretanto, para resistir no contexto atual, será necessário ultrapassar esforços pontuais e investir em mapeamento de ações, formação de redes e constituição de grupos com maiores capacidades de mobilização a fim de incidir na formulação de políticas públicas.

Veloso e Martins (2020) explicam a importância do trabalho comunitário, mas confirmam a importância de políticas públicas, já que não cabe a essas organizações resolver problemas estruturais de saneamento, sistema de saúde ou de ajuda financeira aos trabalhadores. Afirmam, assim, que é preciso que existam políticas públicas que garantam os direitos mínimos para a população favelada. No fim da crise, será importante reconhecer que foi essa mobilização social que evitou o caos completo. As diversas iniciativas nas favelas assumiram responsabilidades distintas, tanto no âmbito da saúde como da assistência, e permitiram uma resposta mais contextualizada à pandemia. Isso demonstra a enorme capacidade e o potencial das favelas e de seus moradores, destoando, mais uma vez, das recorrentes representações negativas associadas a esses espaços.

\section{Repensar as favelas como espaços de resistência}

Como analisam Fleury e Menezes (2020, p. 279), sempre existiram carências nas favelas, mas quando tais carências suscitam demandas e acionam ações coletivas, está se falando de potências. Lideranças e ativistas locais lançaram mão de seus contatos externos e sua capilaridade para assegurar, por exemplo, informação, sanitização, atendimento remoto, proteção (máscaras e álcool em gel), pias para lavagem das mãos e alimentação (cesta básica) para as famílias vulneráveis. Segundo Tiago Firmino, guia turístico de 39 anos, que voluntariamente desinfeta as ruas estreitas da Favela Santa Marta, "o coronavírus é só mais 
um problema para os moradores e a favela. Aqui já morremos de bala perdida, problemas sanitários e tantos outros problemas comuns". ${ }^{17}$

Ora, a mobilização nas favelas contra a pandemia demonstra a capacidade de seus moradores em responder a eventos extremos. Cunha et al.(2015), a partir do caso do Coletivo Juntos pelo Alemão, sustentam que a experiência coletiva de resistência nesses contextos se traduz na criação de redes de apoio e troca de informações com a retomada de fóruns coletivos de debate e intervenção. Se a provisoriedade é a marca das políticas voltadas para as favelas, como afirmam os autores, "a dimensão da permanência e do pertencimento encontra-se presente, por meio de suas lutas comunitárias ou mesmo de seus projetos de moradias, construídas em um esforço coletivo e em suas redes de sociabilidade, tecidas ao longo dos anos" (p. II6).

Ananya Roy (2017) corrobora com esse entendimento quando utiliza a expressão "urbanismo subalterno" como forma de reconhecimento a espaços de vulnerabilidade e formas de agência popular que muitas vezes permanecem invisíveis e negligenciadas nos arquivos e anais da teoria urbana. Nesse contexto, Benjamin (apud ROY, 2017, p. I2) sustenta que o urbanismo das favelas é necessariamente "subversivo" e possui uma "consciência política que se recusa a ser disciplinada pelas ONGs e pelos ativistas progressistas bem-intencionados".

Nesse mesmo sentido, Cunha et al. (2015) sublinham a importância do conhecimento produzido nas favelas, identificando que os movimentos de favelas, diante de situações extremas, buscam enfrentar as invisibilidades e o silêncio da sociedade frente à negação histórica de direitos aos moradores desses territórios, de modo a romper com as dificuldades de circulação de discursos contra-hegemônicos sobre esses locais. Tais lutas demonstram, ao contrário, um fino conhecimento dos moradores. Garantir a memória dessas iniciativas é ao mesmo tempo um dever e uma denúncia à resposta criminosa dos poderes públicos à pandemia.

É importante valorizar tais discursos, uma vez que os saberes produzidos circulam em espaços restritos e são sistematicamente negligenciados por instituições, especialistas e sistemas públicos de informação (CUNHA et al., 2015). As intervenções dos poderes públicos não têm sido suficientes para responder à pandemia. Os governos são negligentes e têm oferecido soluções paliativas para esse problema, o que reafirma a necessidade de identificação, reconhecimento, construção e difusão de formas de resistência social no âmbito das favelas. Os discursos produzidos nas favelas devem ser valorizados não somente quando

\footnotetext{
${ }^{17}$ Ver: <https://www.em.com.br/app/noticia/nacional/2020/04/24/interna_nacional,1141554/coronavirus-iniciativascomunitarias-substituem-o-papel-do-estado-nas.shtml>.
} 
abordam questões impostas às próprias favelas, mas também em relação à toda a sociedade. Assim, parte da solução da crise vindoura pode estar nas soluções construídas nas favelas.

As inovações elaboradas pelos moradores das favelas no contexto da pandemia convidam o Estado e os diferentes segmentos da sociedade ao enfrentamento das graves injustiças sociais e raciais do Rio de Janeiro. Destacam-se, assim, que tais inovações não se limitam aos desafios impostos pela pandemia, mas indicam possibilidades de emergência de novas formas societárias, ou seja, demonstram que voltar ao "normal" do pré-covid não é e nem pode ser o objetivo ao sair da crise atual.

\section{Referências}

ANTUNES, R. Coronavírus: o trabalho sob fogo cruzado (pandemia capital). Boitempo: São Paulo, 2020.

ANTUNES, R.; ALVES, G. As mutações no mundo do trabalho na era da mundialização do capital. Educ. Soc., Campinas, v. 25, n. 87, p. 335-35I, maio/ago. 2004. Disponível em: $<$ https://www.scielo.br/j/es/a/FSqZN7YDckXnYwfqSWqgGPp/?lang=pt\&format=pdf $>$. Acesso em: 06 ago. 202I.

CLAPP, A. et al. A crise provocada pela COVID-I9: antigos problemas em um novo cenário. In: LOLE, A. et al.(Orgs.). Para além da quarentena: reflexões sobre crise e pandemia. Rio de Janeiro: Mórula Editorial, 2020. p.I46-156.

CUNHA, M. B. da et al. O desastre no cotidiano da favela: reflexões a partir de três casos no Rio de Janeiro. Revista OSocial em Questão, n. 33, 2015, p.95-122.

FERREIRA, D. de M. A mercantilização da política de saúde brasileira: análise do fundo público no período neoliberal. SEMINÁRIO CENTROS - CRISE E MUNDO DO TRABALHO NO BRASIL: DESAFIOS PARA A CLASSE TRABALHADORA, 6., 20I8, Fortaleza. Anais... Fortaleza: UECE, 2018.

FLEURY, S.; MENEZES, P. Pandemia nas favelas: entre carências e potências. Saúde em debate, v. 44, n. 4,2020 , p.267-280.

FREIRE, P. Pedagogia da autonomia: saberes necessários à prática educativa. São Paulo: Paz e Terra, 1996.

GONÇALVES, R. S. "São as águas de março fechando o verão...”: chuvas e políticas urbanas nas favelas cariocas, Revista Acervo, n. 28, 2015.

GONÇALVES, R. S.; MACIEL, G. G. Covid-ı 9 e as formas de resistência social nas favelas cariocas. In: MAGALHÃES, A. et al. Cidades: dilemas, desafios e perspectivas. Rio de Janeiro: Editora UVA, 2020, p. I57-I74. 
GRUPO ECO. A Covid-I9 na Favela Santa Marta. Mortes ocorridas na favela no período de fevereiro a junho de 2020, Rio de Janeiro: Mimeo, 2020.

HALL, C. M. Planejamento turístico, políticas, processos e relacionamentos. São Paulo: Contexto, $200 \mathrm{I}$.

HARVEY, D. Política anticapitalista em tempos de coronavírus. Boitempo, São Paulo, 2020. Disponível em: <https://blogdaboitempo.com.br/2020/o3/24/david-harvey-politica-anticapitalista-emtempos-de-coronavirus/>. Acesso em: 04 ago. 2020.

MBEMBE, A. Necropolítica. Arte \& Ensaios, n. 32, 2016, p. I23-I5I.

MENEZES, P. et. al. Painéis comunitários: a disputa pela verdade da pandemia nas favelas cariocas. Horizontes Antropológicos, n. 59, 202I, p. I09-I28.

OLIVEIRA, A. M. de. Planejamento participativo como instrumento de desenvolvimento turístico responsável. Caderno Virtual de Turismo, v. 8, n. 3, 2008.

ROY, A. Cidades faveladas. Repensando o urbanismo subalterno. Revista E-Metropolis, n. 3I, 2OI7, p. 6-2I.

TORRES, V. Domésticas estão entre as mais expostas à contaminação pela Covid-I9. UFRN, Rio Grande do Norte, 30 abr. 2020. Imprensa, Notícias. Disponível em:

$<$ https://ufrn.br/imprensa/noticias/35459/domesticas-estao-entre-as-mais-expostas-acontaminacao-pela-covid-I9>. Acesso em: 05 ago. 2020.

VELOSO, F.; MARTINS, G. Coronavírus no dia a dia das favelas, parte 5: resposta da Maré frente ao desafio de informar. Rio on Watch, Rio de Janeiro, 15 abr. 2020. Disponível em: $<$ https://rioonwatch.org.br/?p=46504 $>$. Acesso em: abr. 2020.

ZAOUAL, H. Do turismo de massa ao turismo situado. Quais as transições. In: BARTHOLO, R. et al. (Orgs.). Turismo de base comunitária: diversidade de olhares e experiências brasileiras. Rio de Janeiro: Letra e Imagem; COPPE-UFRJ, 2009. 